\title{
Modelling the Variability and the Anisotropic Behaviour of Crack Growth in SLM Ti-6Al-4V
}

\author{
Rhys Jones ${ }^{1,2, *(D)}$, Calvin Rans ${ }^{3}$, Athanasios P. Iliopoulos ${ }^{4}$, John G. Michopoulos ${ }^{4}$, Nam Phan ${ }^{5}$ and \\ Daren Peng ${ }^{1}$ D
}

1 Centre of Expertise for Structural Mechanics, Department of Mechanical and Aerospace Engineering, Monash University, Clayton, VIC 3800, Australia; daren.peng@monash.edu

2 ARC Industrial Transformation Training Centre on Surface Engineering for Advanced Materials, Faculty of Science, Engineering and Technology, Swinburne University of Technology, John Street, Hawthorn, VIC 3122, Australia

3 Faculty of Aerospace Engineering, Delft University of Technology, Kluyverweg 1, 2629 HS Delft, The Netherlands; C.D.Rans@tudelft.nl

4 Computational Multiphysics Systems Laboratory, Code 6394, Center for Materials Physics and Technology, US Naval Research Laboratory, Washington, DC 20375, USA; athanasios.iliopoulos@nrl.navy.mil (A.P.I.); john.michopoulos@nrl.navy.mil (J.G.M.)

5 Structures Division, Naval Air Systems Command, Patuxent River, MD 20670, USA; nam.phan@navy.mil

* Correspondence: rhys.jones@monash.edu

Citation: Jones, R.; Rans, C.; Iliopoulos, A.P.; Michopoulos, J.G.; Phan, N.; Peng, D. Modelling the Variability and the Anisotropic Behaviour of Crack Growth in SLM Ti-6Al-4V. Materials 2021, 14, 1400. https://doi.org/10.3390/ma14061400

Academic Editor: Tuhin Mukherjee

Received: 16 February 2021

Accepted: 11 March 2021

Published: 13 March 2021

Publisher's Note: MDPI stays neutral with regard to jurisdictional claims in published maps and institutional affiliations.

Copyright: (c) 2021 by the authors. Licensee MDPI, Basel, Switzerland. This article is an open access article distributed under the terms and conditions of the Creative Commons Attribution (CC BY) license (https:// creativecommons.org/licenses/by/ $4.0 /)$.

\begin{abstract}
The United States Air Force (USAF) Guidelines for the Durability and Damage Tolerance (DADT) certification of Additive Manufactured (AM) parts states that the most difficult challenge for the certification of an AM part is to establish an accurate prediction of its DADT. How to address this challenge is the focus of the present paper. To this end this paper examines the variability in crack growth in tests on additively manufactured (AM) Ti-6Al-4V specimens built using selective layer melting (SLM). One series of tests analysed involves thirty single edge notch tension specimens with five build orientations and two different post heat treatments. The other test program analysed involved ASTM standard single edge notch specimens with three different build directions. The results of this study highlight the ability of the Hartman-Schijve crack growth equation to capture the variability and the anisotropic behaviour of crack growth in SLM Ti-6Al-4V. It is thus shown that, despite the large variability in crack growth, the intrinsic crack growth equation remains unchanged and that the variability and the anisotropic nature of crack growth in this test program is captured by allowing for changes in both the fatigue threshold and the cyclic fracture toughness.
\end{abstract}

Keywords: additive manufacture; SLM Ti-6Al-4V; variability; anisotropy; fatigue crack growth

\section{Introduction}

The regulatory requirements associated with additively manufactured (AM) parts for both civil and military aircraft are summarised in [1-3]. As noted in [3,4], and in the United Staes Air Force (USAF) airworthiness certification standard MIL-STD-1530D [5], it is essential that the variability in the crack growth rates be understood. This requirement is also highlighted in USAF Structures Bulletin EZ-19-01 [4], which specifically addresses the USAF guidelines for the durability and damage tolerance (DADT) certification of additively manufactured aircraft structural parts. Indeed, the ability to accurately assess the variability in crack growth is particularly important when performing the risk of failure analysis mandated in the US Joint Services Structural Guideline JSSG2006 [6]. As explained in Section 5.3 of MIL-STD-1530D [5] analysis is central to airworthiness certification, and the purpose of experimental tests is "to validate or correct analysis methods and results, and to demonstrate that requirements are achieved".

The study by Virkler and Hillberry [7] is acknowledged to be the first paper to highlight the variability that can arise in the measured fatigue (long) crack growth rates 
(da/dN, where $a$ is the crack length and $N$ is the number of cycles) in conventionally manufactured metals. Whilst the paper by Iliopoulos et al. [8] highlighted the extensive variability that is associated with long cracks in Ti-6Al-4V built using a number of different AM processes, the paper by Rans et al. [9], which presented the $d a / d N$ versus $\Delta K$ curves associated with thirty Ti-6Al-4V single edge notch tension (SENT) specimens built using selective laser melt (SLM), is arguably the first to present a similar in depth study to that of Virkler where attention was focused on a single AM process. Unfortunately, as explained in [8], the expression used in [9] to determine the range in the stress intensity factor in a load cycle $\left(\Delta K=K_{\max }-K_{\min }\right.$, where $K_{\max }$ and $K_{\min }$, are the maximum and minimum values of the stress intensity factor in a cycle) was inaccurate. Whilst correct expression for $\Delta K$ was given in [8] the corresponding $d a / d N$ versus $\Delta K$ were not. Consequently, one of the primary purposes of this paper is to present the accurate curves associated with these thirty SLM Ti-6Al-4V single edge notch tension (SENT) specimens and thereby highlight the extent of the variability associated with crack growth in SLM Ti-6Al-4V.

The paper by Molent and Jones [10] was the first to reveal that the variability in the $d a / d N$ versus $\Delta K$ curves given in [7] could be captured by allowing for the variability in the fatigue threshold term $\Delta K_{t h r}$ in Equation (2) the Hartman-Schijve equation [11], viz.

$$
d a / d N=D(\Delta \kappa)^{p}
$$

The terms $D$ and $p$ are constants, and $\Delta \kappa$ is the crack driving force as given by Schwalbe in [12], viz.

$$
\Delta \kappa=\left(\Delta K-\Delta K_{t h r}\right) /\left(1-\left(K_{\max } / A\right)\right)^{1 / 2}
$$

where the term $A$ is the cyclic fracture toughness. It has subsequently been shown [8,13-18] that the variability in crack growth in AM materials can often be accounted for by allowing for the variability in the fatigue threshold term $\Delta K_{\text {thr }}$ and the cyclic fracture toughness term $(A)$.

To address the main issue of accurately predicting the DADT, this paper also focuses in evaluating if this formulation can also be used to account for the variability in the $d a / d N$ versus $\Delta K$ curves presented by Ran's et al. in [9]. The outcome of this initial study is that when $d a / d N$ is plotted as a function of $\Delta \kappa$ then each of these thirty curves essentially collapse onto the same master curve obtained for the growth of both long and small cracks in conventionally manufacture Ti-6Al-4V. It should be stressed that, this seminal finding represents the first time that any fracture mechanics-based study has been shown to be able to capture the underlying response in such a large cross section of tests on AM specimens built using a single AM facility. This example is particularly important given that MIL-STD1530D mandates the use of fracture mechanics-based analyses in the certification process and that USAF Structures Bulletin EZ-19-01 states that the most difficult challenge for AM structural is to establish an "accurate prediction of structural performance" specific to DADT.

This study is complemented by a subsequent investigation into the ability of Equations (1) and (2) to capture the anisotropic behaviour of crack growth in ASTM compact tension (CT) SLM Ti-6Al-4V specimens. As such the studies presented in this paper illustrate how to address the challenge delineated in Structures Bulletin EZ-19-01, namely how to allow for the variability seen in crack growth in AM parts.

\section{Materials and Methods}

The data analysed in the present paper are taken either journals that are both peer reviewed and publicly available, refereed Conferences and texts that are publicly available (ISBN numbers are given in the associated reference), or from Google searches. Of these references ten are SCOPUS listed Journals, and five are available on various US government websites. The Book Chapters and Books referenced can all be found listed in SCOPUS, one reference can be found on the FAA website. The keywords used to find the references: Additive manufacturing, durability, damage tolerance, variability, and Hartman-Schijve. The exception to this is [2] which was presented at the Proceedings Indian Structural 
Integrity Society, 3rd Structural Integrity Conference and Exhibition (SICE), IIT, Mumbai, India, 11 December 2020 and which is not as yet available online.

\section{Modelling the Variability in SLM TI-6AL-4V}

Let us first examine the variability in the $d a / d N$ versus $\Delta K$ curves given in [9] for crack growth in SLMTi-6Al-4V. In this study thirty $R=0.1$ tests were performed on single edge notch tension (SENT). The specimens tested had five different build orientations $(0,30$, 45, 60 and, 90 degrees), and two different post heat treatments, namely: (a) specimens annealed at $735^{\circ} \mathrm{C}$ and (b) specimens annealed at $735^{\circ} \mathrm{C}$ and then subjected to hot isostatic pressing (HIP) for two hours. In [9] the build direction was defined relative to the crack in the SENT specimen. (By this it is meant that a build direction of 90 degrees corresponds to the case when the crack was at nright angle to the build direction.) Details of the processes, and the specimen identifiers are given in Table 1.

Table 1. Notation associated with the specimen tests reported in [9].

\begin{tabular}{|c|c|c|}
\hline Build Angle & Treatment & Descriptor \\
\hline $0^{\circ}$ & annealed at $735^{\circ} \mathrm{C}$ & $00-2$ \\
\hline ibid & ibid & $00-3$ \\
\hline ibid & ibid & $00-4$ \\
\hline ibid & $\begin{array}{c}\text { annealed at } 735^{\circ} \mathrm{C} \text { and then } \\
\text { HIPed for }\end{array}$ & $00-6$ \\
\hline ibid & $2 \mathrm{~h}$ at $920^{\circ} \mathrm{C}$ and $1000 \mathrm{bar}$ & $00-7$ \\
\hline ibid & ibid & $00-8$ \\
\hline $30^{\circ}$ & annealed at $735^{\circ} \mathrm{C}$ & $30-2$ \\
\hline ibid & ibid & $30-3$ \\
\hline ibid & ibid & $30-4$ \\
\hline ibid & $\begin{array}{c}\text { annealed at } 735^{\circ} \mathrm{C} \text { and then } \\
\text { HIPed for } 2 \mathrm{~h} \text { at } 920^{\circ} \mathrm{C} 1000 \\
\text { bar }\end{array}$ & $30-6$ \\
\hline ibid & ibid & $30-7$ \\
\hline ibid & ibid & $30-8$ \\
\hline $45^{\circ}$ & annealed at $735^{\circ} \mathrm{C}$ & $45-2$ \\
\hline ibid & ibid & $45-3$ \\
\hline ibid & ibid & $45-4$ \\
\hline ibid & $\begin{array}{c}\text { annealed at } 735^{\circ} \mathrm{C} \text { and then } \\
\text { HIPed for }\end{array}$ & $45-5$ \\
\hline ibid & 2 hrs $920^{\circ} \mathrm{C} 1000$ bar & $45-6$ \\
\hline ibid & ibid & $45-8$ \\
\hline $60^{\circ}$ & annealed at $735^{\circ} \mathrm{C}$ & $60-2$ \\
\hline ibid & ibid & $60-3$ \\
\hline ibid & $\begin{array}{c}\text { annealed at } 735^{\circ} \mathrm{C} \text { and then } \\
\text { HIPed for }\end{array}$ & $60-6$ \\
\hline ibid & $2 \mathrm{hrs}$ at $920^{\circ} \mathrm{C}$ and $1000 \mathrm{bar}$ & $60-7$ \\
\hline ibid & ibid & $60-8$ \\
\hline $90^{\circ}$ & annealed at $735^{\circ} \mathrm{C}$ & $90-2$ \\
\hline ibid & ibid & $90-3$ \\
\hline ibid & ibid & $90-4$ \\
\hline ibid & $\begin{array}{l}\text { annealed at } 735^{\circ} \mathrm{C} \text { and then } \\
\text { HIPed for } 2 \mathrm{~h} 920^{\circ} \mathrm{C} 1000 \mathrm{bar}\end{array}$ & $90-5$ \\
\hline ibid & ibid & $90-6$ \\
\hline ibid & ibid & $90-8$ \\
\hline
\end{tabular}

The variability in the thirty $d a / d N$ versus $\Delta K$ curves is shown in Figure 1. (As noted in [8] the $d a / d N$ versus $\Delta K$ curves given in [9] were incorrect since the expression used to determine $\Delta K$ was incorrect. Whilst this error was corrected in [8], only a few selected $d a / d N$ versus $\Delta K$ curves were given.) Figure 2 reveals that the $d a / d N$ versus $\Delta K$ curves are largely bounded above by that of specimen $30-3$, and below by specimen $90-8$, which is HIPed. For comparison Figure 1 also contains the $R=-1 d a / d N$ versus $\Delta K$ curve determined in [17] 
for the growth of a short surface crack in an AM Ti-6Al-4V cylindrical specimen, that was fabricated using an M290 Laser Beam Powder Bed Fusion (LB-PBF) facility, subjected to constant amplitude loading with a maximum stress of $910 \mathrm{MPa}$. This curve is labelled LB-PBF1. The cyclic fracture toughness $(A)$ of the material in this test was approximately $85 \mathrm{MPa} \sqrt{ } \mathrm{m}$, and $\Delta K_{t h r}$ was approximately $0.1 \mathrm{MPa} \sqrt{ } \mathrm{m}$, see [17]. Figure 1 reveals that the crack growth rate in specimen 30-3 is similar to the growth rate seen by the surface crack in specimen LB-PBF1.

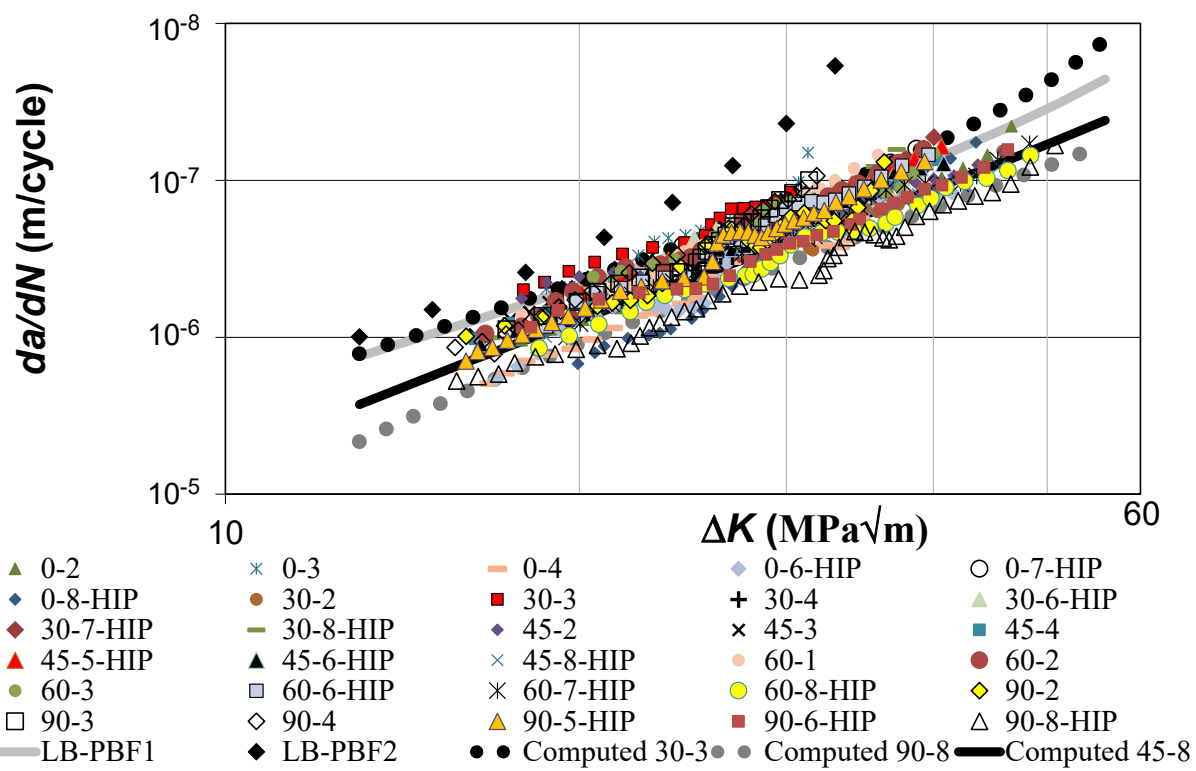

Figure 1. Variability in the thirty SLM Ti-6Al-4V tests reported in [9].

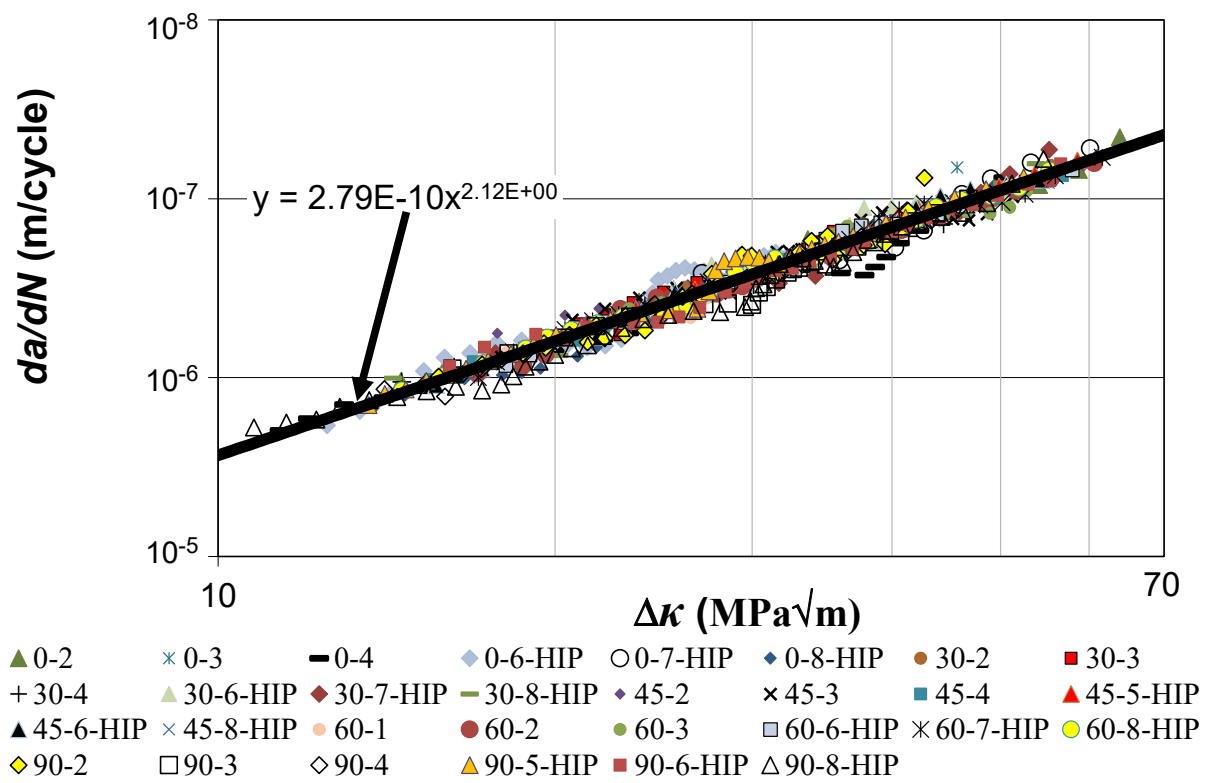

Figure 2. Hartman-Schijve representation of the thirty SLM Ti-6Al-4V tests.

To further illustrate the variability associated with AM Ti-6Al-4V Figure 1 also contains the $R=-1 d a / d N$ versus $\Delta K$ curve determined in [17] for a short surface crack in a specimen built using a Renishaw AM250 LB-PBF machine. In this instance the maximum applied stress was $268 \mathrm{MPa}$. This curve is labelled LB-PBF2. The cyclic fracture toughness $(A)$ of the material in this test was found to be approximately $37 \mathrm{MPa} \sqrt{ } \mathrm{m}$ and the fatigue threshold term $\left(\Delta K_{t h r}\right)$ was approximately $0.1 \mathrm{MPa} \sqrt{ } \mathrm{m}$, see [17]. Here, it should be noted 
that [17] explained that the difference in the crack growth rates in these two LB-PBF tests was primarily due to the differences in the cyclic fracture toughness's.

Figure 2 reveals that if the curves shown in Figure 1 are plotted with $d a / d N$ as a function of $\Delta \kappa$, then (allowing experimental error) the scatter in these thirty curves essentially vanishes. Figure 2 also reveals that these thirty tests lie on the same $d a / d N$ versus $\Delta \kappa$ curve determined for both long and short cracks in conventionally and AM Ti-6Al-4V, viz.

$$
\text { da } / d N=2.79 \times 10^{-10}\left[\left(\Delta K-\Delta K_{\text {thr }}\right) /\left(1-K_{\max } / A\right)^{1 / 2}\right]^{1.99}
$$

The values of $\Delta K_{t h r}$ and $A$ used in Figure 2, and the corresponding values of the coefficient of determination $\left(R^{2}\right)$ are given in Table 2. (The mean value of the coefficients of determination given in Table 2 is approximately 0.96.) Here, it should be recalled that as shown in [13] the ASTM definition of the fracture toughness $\left(\Delta K_{t h}\right)$, which is arbitrarily chosen to be the value of $\Delta K$ at a crack growth rate $d a / d N$ of $10^{-10} \mathrm{~m} /$ cycle [19], is related to $\Delta K_{t h r}$ is via the expression:

$$
\Delta K_{\mathrm{th}}=\Delta K_{\mathrm{thr}}+0.62
$$

\begin{tabular}{|c|c|c|c|c|}
\hline Build Angle & Descriptor & $\Delta K_{t h r}(\mathrm{MPa} \sqrt{ } \mathrm{m})$ & $A(\mathrm{MPa} \sqrt{ } \mathrm{m})$ & $\begin{array}{c}\text { Coefficient of } \\
\text { Determination }\left(R^{2}\right)\end{array}$ \\
\hline $0^{\circ}$ & $00-2$ & 5.10 & 88.0 & 0.97 \\
\hline ibid & $00-3$ & 1.50 & 54.5 & 0.95 \\
\hline ibid & $00-4$ & 7.80 & 73.0 & 0.91 \\
\hline ibid & 00-6 (HIPed) & 5.40 & 107.0 & 0.96 \\
\hline ibid & 00-7 (HIPed) & 4.92 & 67.0 & 0.95 \\
\hline ibid & 00-8 (HIPed) & 8.20 & 70.0 & 0.99 \\
\hline $30^{\circ}$ & $30-2$ & 5.90 & 105.0 & 0.95 \\
\hline ibid & $30-3$ & 0.10 & 63.5 & 0.97 \\
\hline ibid & $30-4$ & 4.10 & 73.0 & 0.97 \\
\hline ibid & 30-6 (HIPed) & 1.30 & 85.0 & 0.91 \\
\hline ibid & 30-7 (HIPed) & 2.20 & 73.0 & 0.93 \\
\hline ibid & 30-8 (HIPed) & 2.55 & 65.0 & 0.97 \\
\hline $45^{\circ}$ & $45-2$ & 0.10 & 134.0 & 0.98 \\
\hline ibid & $45-3$ & 1.90 & 73.0 & 0.94 \\
\hline ibid & $45-4$ & 2.70 & 85.0 & 0.99 \\
\hline ibid & 45-5 (HIPed) & 1.50 & 76.0 & 0.99 \\
\hline ibid & 45-6 (HIPed) & 2.40 & 90.0 & 0.98 \\
\hline ibid & 45-8 (HIPed) & 3.10 & 128.0 & 0.99 \\
\hline ibid & $60-1$ & 3.00 & 61.0 & 0.99 \\
\hline ibid & $60-2$ & 1.90 & 74.0 & 0.99 \\
\hline $60^{\circ}$ & $60-3$ & 0.10 & 98.3 & 0.92 \\
\hline ibid & 60-6 (HIPed) & 3.70 & 70.0 & 0.99 \\
\hline ibid & 60-7 (HIPed) & 3.70 & 116.0 & 0.97 \\
\hline ibid & 60-8 (HIPed) & 5.00 & 140.0 & 0.99 \\
\hline ibid & $90-2$ & 1.95 & 93.8 & 0.85 \\
\hline $90^{\circ}$ & $90-3$ & 5.90 & 49.7 & 0.98 \\
\hline ibid & $90-4$ & 5.01 & 51.0 & 0.99 \\
\hline ibid & 90-5 (HIPed) & 4.00 & 80.0 & 0.98 \\
\hline ibid & 90-6 (HIPed) & 3.80 & 123 & 0.99 \\
\hline ibid & 90-8 (HIPed) & 6.20 & 168.0 & 0.96 \\
\hline
\end{tabular}

Table 2. Values used in Figure 2. 
To further illustrate how the variability in these tests can be captured using Equation (2) Figure 1 also presents plots of the computed curves for specimens 30-3 and $90-8$ as well as for specimen 45-8, which is HIPed and which represents a mid-range (in the context of the present study) crack growth curve. These computed curves were determined using Equation (2) together with the values of $A$ and $\Delta K_{\text {thr }}$ given in Table 2.

To help quantify the effect of the HIPing process Table 3 presents the mean and standard deviations associated with specimens both with and without HIPing. As in [13,14] we see that in contrast to conventionally manufactured specimens the variability associated with the cyclic fracture toughness $(A)$ is quite large. The mean value of $A$ for the annealed specimens of approximately $79 \mathrm{MPa} \sqrt{ } \mathrm{m}$ is similar to the mean value of approximately $83 \mathrm{MPa} \sqrt{ } \mathrm{m}$ associated with the forty different AM Ti-6Al-4V specimens analysed in $[8,13]$. The standard deviation associated with the SLM specimens is approximately $23 \mathrm{MPa} \sqrt{ } \mathrm{m}$. This value is lower than the value of $49 \mathrm{MPa} \sqrt{ } \mathrm{m}$ obtained for the specimens analysed in $[8,13]$. This is to be expected since the later value covers specimens fabricated using a variety of different AM processes, viz. SLM, Direct Metal Deposition (DMLS), Laser Engineered Net Surface (LENS), etc., and includes specimens left as built, after annealing, and/or after HIPing. When specimens that were either left in the as fabricated state or HIPed are removed from the data being considered then the mean value increases slightly to approximately $89 \mathrm{MPa} \sqrt{ } \mathrm{m}$ with a standard deviation of approximately $57 \mathrm{MPa} \sqrt{ } \mathrm{m}$.

Table 3. Mean and standard deviations of $\Delta K_{t h r}$ and $A$ associated with SLM Ti-6Al-4V specimens with and without HIPing.

\begin{tabular}{ccc}
\hline & Mean Value & Standard Deviation \\
\hline Annealed at $735^{\circ} \mathrm{C}$ & & \\
\hline$A(\mathrm{MPa} \times \sqrt{ } \mathrm{m})$ & 78.6 & 23.0 \\
\hline$\Delta K_{\text {thr }}(\mathrm{MPa} \times \sqrt{ } \mathrm{m})$ & 3.2 & \\
\hline $\begin{array}{c}\text { Annealed at } 735{ }^{\circ} \mathrm{C} \text { and then } \\
\text { HIPed for } 2 \text { hrs at } 920^{\circ} \mathrm{C} 1000 \text { bar }\end{array}$ & & 31.6 \\
\hline$A(\mathrm{MPa} \times \sqrt{ } \mathrm{m})$ & 96.6 & 1.9 \\
\hline$\Delta K_{\text {thr }}(\mathrm{MPa} \times \sqrt{ } \mathrm{m})$ & 3.8 & \\
\hline
\end{tabular}

Table 3 reveals that the mean value of $A$ for the SLMS specimens that were both annealed and HIPed is approximately $96.6 \mathrm{MPa} \sqrt{ } \mathrm{m}$. At first glance this would suggest that HIPing is advantageous. However, the standard deviation associated with these two sets of SLM specimens is quite large, and hence caution is urged with respect to this observation.

Table 3 also reveals that the mean values of the fatigue threshold term $\Delta K_{t h r}$ associated with the annealed (only) and the annealed and HIPed specimens are 3.2 and $3.8 \mathrm{MPa} \sqrt{ } \mathrm{m}$, respectively. The corresponding standard deviations are 2.4 and $1.9 \mathrm{MPa} \sqrt{ } \mathrm{m}$. These values are comparable with the mean values of 3.3 and $3.5 \mathrm{MPa} \sqrt{ } \mathrm{m}$ associated with all of the forty different AM Ti-6Al-4V specimens analysed in $[8,13]$, and with the value obtained when specimens that either were left in the as fabricated state or HIPed are removed from the data being considered. However, the mean values are misleading in that in several of these tests the value of $\Delta K_{t h r}$ was significantly lower.

Crack Growth in ASTM Compact Tension SLM Ti-6Al-4V Specimens as Function of Crack Orientation Relative to the Build Direction

Let us next consider the $R=0.1$ crack growth histories presented in [20] for crack growth in a $10 \mathrm{~mm}$ thick ASTM compact tension (CT) specimen with cracks at $0^{\circ}, 45^{\circ}$, and $90^{\circ}$ to the build direction in SLM Ti-6Al-4V. The measured and computed crack growth histories are shown in Figure 3 where we see excellent agreement. The values of $\Delta K_{t h r}$ and $A$ used in Figure 3 are given in Table 4. 


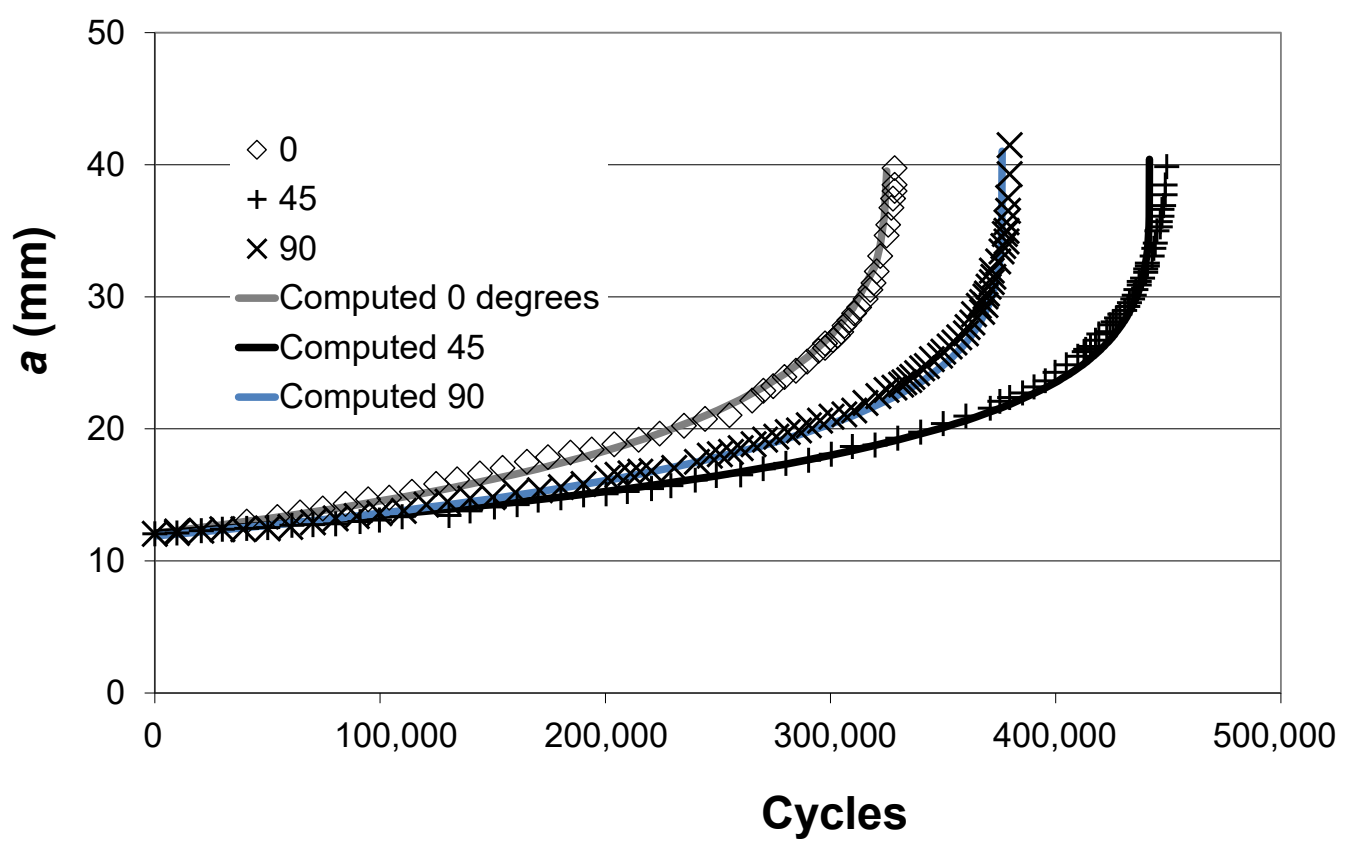

Figure 3. Measured and computed crack growth histories for the SLM Ti-6Al-4V tests reported in [20].

Table 4. Values used in Figure 3.

\begin{tabular}{ccc}
\hline Build Direction & $\Delta \boldsymbol{K}_{\text {thr }}(\mathbf{M P a} \times \sqrt{ } \mathbf{m})$ & $A(\mathbf{M P a} \sqrt{ } \mathbf{m})$ \\
\hline $0^{\circ}$ & 2.0 & 71 \\
$45^{\circ}$ & 3.8 & 52 \\
$90^{\circ}$ & 3.15 & 48.5 \\
\hline
\end{tabular}

\section{Implications for the Durability Analysis of AM Parts}

USAF Structures Bulletin EZ-19-01 [3] explains that durability analysis is essential to the certification of AM parts. Lincoln and Melliere [21], as part of the USAF F-15 program, and $[11,14]$ have shown that a durability analysis necessitates the use of the associated small crack $d a / d N$ versus $\Delta K$ curve (a similar statement is contained in Appendix X3 of the ASTM fatigue test standard E647-15 [19]). Structures Bulletin EZ-19-01 [3] also requires the use of a minimum equivalent initial damage size (EIDS) of $0.254 \mathrm{~mm}(0.01 \mathrm{inch})$. (This value is taken from the Joint Services Structural Guidelines 2006 [3].) Whereas the paper by Virkler and Hillberry [7] is acknowledged to be first to illustrate the variability associated with long cracks in metals, the paper by Kundu et al. [16], which presented the crack growth histories associated with twenty three small surface breaking cracks with length scales of the order of $0.254 \mathrm{~mm}$ in AA7050-T7451 aluminium alloy specimens, was (to the best of the authors knowledge) the first to examine the variability in the growth of small surface breaking cracks with sizes comparable to that of the EIDS required in [3]. This study revealed that the variability in the crack growth histories was accurately captured allowing for variability in $\Delta K_{t h r}$. The resultant variability in the $d a / d N$ versus $\Delta K$ curves associated with these twenty-three (small) surface breaking cracks is shown in Figure 4.

Of course, the variability seen in Figure 4 is associated with a limited data set, and as such it may not necessarily capture the extent of the true variability in the material properties. To account for such limited data sets Niu [22] and Rouchon [23] suggest adopting a statistical approach whereby the 'A basis' and 'B basis' properties are determined. An 'A basis' mechanical property value equals the mean value minus three standard deviations and is the value above which at least $99 \%$ of the population of values is expected to fall with a confidence of $95 \%$ [22]. A 'B basis' mechanical property value equals the mean value minus two standard deviations and is the value above which at least $95 \%$ of the population 
of values is expected to fall with a confidence of $95 \%$ [22]. The values of $\Delta K_{\text {thr }}$ given in [16] for these twenty-three cracks are given in Table 5 . The mean value of $\Delta K_{t h r}$ is approximately $0.80 \mathrm{MPa} \sqrt{ } \mathrm{m}$ and the standard deviation $(\sigma)$ is approximately $0.24 \mathrm{MPa} \sqrt{ } \mathrm{m}$. This yields a Mean- $3 \sigma$ of approximately $0.1 \mathrm{MPa} \sqrt{ } \mathrm{m}$. This curve is also shown in Figure 4 . Interestingly the Mean- $3 \sigma$ curve shown in Figure 4 for these size EIDS is close to that given in [24-26] for the growth of "small" cracks from small near micron size surface discontinuities in 7050-T7451. It is also the same as the values determined in [17] for the growth of small surface breaking cracks in LPBF Ti-6Al-4V.

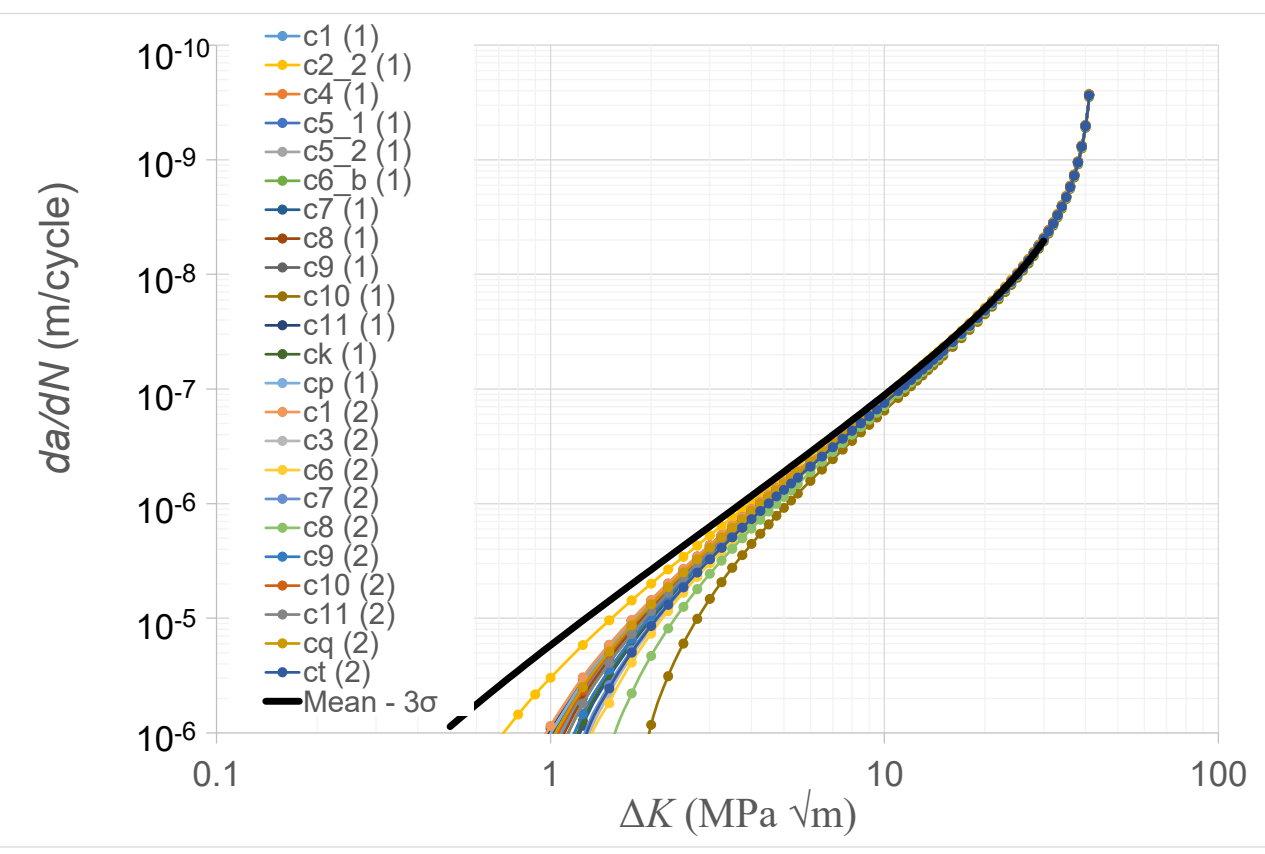

Figure 4. Variability in the crack growth curves for the twenty-three small surface breaking cracks in 7050-T7451 specimens [16]. The labelling convention used for these twenty-three cracks is taken from [16].

Taking the results of this study into the variability of near EIDS size surface breaking cracks into consideration, and noting that the fastest growing long crack in the SLM Ti-6Al$4 \mathrm{~V}$ tests given in [9] can be approximated by using Equations (1) and (2) together with a low value for the fatigue threshold term $\Delta K_{t h r}$, it is hypothesised that this phenomena, i.e., that the worst case curve associated with surface breaking cracks with dimensions as per the minimum allowable EIDS given in [3] for the durability analysis of an AM part would also resemble the corresponding small crack curve, may also hold for AM parts. However, testing is required to evaluate this hypothesis.

Table 5. Values of the term $\Delta K_{t h r}$ given in [16].

\begin{tabular}{|c|c|}
\hline Crack Descriptor & $\Delta K_{t h r}(\mathrm{MPa} \sqrt{ } \mathrm{m})$ \\
\hline $\mathrm{c} 1$ & 0.7 \\
\hline c2_2 & 0.35 \\
\hline $\mathrm{c} 4$ & 0.75 \\
\hline c5_1 & 0.8 \\
\hline c5_2 & 0.6 \\
\hline c6_b & 0.75 \\
\hline $\mathrm{c} \overline{7}$ & 0.85 \\
\hline c8 & 0.72 \\
\hline c9 & 0.65 \\
\hline c10 & 1.6 \\
\hline
\end{tabular}


Table 5. Cont.

\begin{tabular}{cc}
\hline Crack Descriptor & $\Delta \boldsymbol{K}_{\text {thr }}(\mathbf{M P a} \sqrt{ } \mathbf{m})$ \\
\hline c11 & 0.61 \\
ck & 0.83 \\
cp & 0.63 \\
c1 & 0.6 \\
c3 & 0.95 \\
c6 & 1 \\
c7 & 0.9 \\
c8 & 1.2 \\
c9 & 0.8 \\
c10 & 0.68 \\
c11 & 0.75 \\
cq & 0.66 \\
\hline
\end{tabular}

\section{Conclusions}

USAF Structures Bulletin EZ-19-01 states that the most difficult challenge for AM structural is to establish an "accurate prediction of structural performance" specific to DADT. It also notes the importance of being able to account for the variability in the crack growth rates associated with AM parts. To meet this challenge the present has examined the variability in the crack growth rates associated with two studies into crack growth in SLM Ti-6Al-4V. One of the studies analysed, involved thirty single edge notch tension specimens with five build orientations and two different post heat treatment methods. The other study involved ASTM standard CT specimens with three different build directions. The results of this analysis highlight the ability of the Hartman-Schijve crack growth equation to capture the variability and the anisotropic behaviour of crack growth in SLM Ti-6Al-4V. This seminal finding represents the first time that any fracture mechanics-based study has been shown to be able to capture the underlying response in such a large cross section of tests on AM specimens built using a single AM facility. This development is central to meeting the certification requirements delineated in MIL-STD-1530D and EZ-19-01.

It is also hypothesised that the worst-case curve associated with surface breaking cracks with dimensions as per the minimum allowable EIDS given in EZ-19-01 for the durability analysis of an AM part should resemble the corresponding small crack curve. However, additional testing is required to evaluate this hypothesis. This finding, once further validated, will have significant implications for the economic life/durability certification of AM parts.

Author Contributions: Conceptualisation and initial analysis-R.J.; Tests on Ti-6Al-4V with different build directions and analysis of the associated data-C.R.; Methodology for determining the constants in the Hartman-Schijve equations-J.G.M.; Analysis of crack growth data to obtain the optimized constants-A.P.I.; Analysis of the test data associated with the ASTM Compact Tension SLM Ti6Al-4V specimens-D.P.; Overview and evaluation of the final report and its relationship to aircraft certification-N.P. All authors have read and agreed to the published version of the manuscript.

Funding: John Michopoulos and Athanasios Iliopoulos acknowledge support for this work by the Office of Naval Research (ONR) through the Naval Research Laboratory's core funding.

Institutional Review Board Statement: Not applicable.

Informed Consent Statement: Not applicable.

Data Availability Statement: Data sharing is not applicable to this article.

Conflicts of Interest: The authors declare no conflict of interest. 


\section{References}

1. Gorelik, M. Regulatory Considerations for AM Qualification and Status of FAA Roadmap. In Proceedings of the Additive Manufacture for Reactor Materials \& Components: Public Meeting, Bethesda, MD, USA, 28-29 November 2017. Available online: https:/ / www.nrc.gov/docs/ML1733/ML17338A886.pdf (accessed on 2 February 2021).

2. Gorelik, M. Lessons Learned for Structural Alloys and Implications for Metal AM F\&DT Considerations. In Proceedings of the Indian Structural Integrity Society, 3rd Structural Integrity Conference and Exhibition (SICE), IIT, Mumbai, India, 11 December 2020.

3. Structures Bulletin EZ-SB-19-01, Durability and Damage Tolerance Certification for Additive Manufacturing of Aircraft Structural Metallic Parts, Wright Patterson Air Force Base, OH, USA. 10 June 2019. Available online: https://daytonaero.com/usafstructures-bulletins-library/ (accessed on 2 February 2021).

4. Hrabe, N.; Barbosa, N.; Daniewicz, S.; Shamsaei, N. Findings from the NIST/ASTM Workshop on Mechanical Behavior of Additive Manufacturing Components, ASTM-NIST Workshop on Mechanical Behavior of Additive Manufactured Components, NIST Advanced Manufacturing Series 100-4. 2016. Available online: https:/ / doi.org/10.6028/NIST.AMS.100-4 (accessed on 2 February 2021).

5. MIL-STD-1530D, Department of Defense Standard Practice Aircraft Structural Integrity Program (ASIP). 13 October 2016. Available online: http:/ / everyspec.com/MIL-STD/MIL-STD.../download.php?spec=MIL-STD-1530D (accessed on 2 February 2021).

6. Department of Defense Joint Service Specification Guide, Aircraft Structures, JSSG-2006. October 1998. Available online: http:/ / everyspec.com/USAF/USAF-General/JSSG-2006_10206/ (accessed on 10 July 2020).

7. Virkler, D.A.; Hillberry, B.M.; Goel, P.K. The Statistical Nature of Fatigue Crack Propagation; Technical Report AFFDL-TR-7843; Air Force Wright Aeronautical Laboratory: Wright Patterson Ai Force Base, OH, USA, 1978. Available online: https: / / apps.dtic.mil/dtic/tr/fulltext/u2/a056912.pdf (accessed on 2 February 2021).

8. Iliopoulos, A.P.; Jones, R.; Michopoulos, J.G.; Phan, N.; Rans, C. Further Studies into Crack Growth in Additively Manufactured Materials. Materials 2020, 13, 2223. [CrossRef] [PubMed]

9. Rans, C.; Michielssen, J.; Walker, M.; Wang, W.; Hoen-Velterop, L. Beyond the orthogonal: On the influence of build orientation on fatigue crack growth in SLM Ti-6Al-4V. Int. J. Fatigue 2018, 116, 344-354. [CrossRef]

10. Molent, L.; Jones, R. The influence of cyclic stress intensity threshold on fatigue life scatter. Int. J. Fatigue 2016, 82, 748-756. [CrossRef]

11. Jones, R. Fatigue crack growth and damage tolerance. Fatigue Fract. Eng. Mater. Struct. 2014, 37, 463-483. [CrossRef]

12. Schwalbe, K.H. On the Beauty of Analytical Models for Fatigue Crack Propagation and Fracture-A Personal Historical Review. J. ASTM Int. 2010, 7, 3-73. [CrossRef]

13. Jones, R.; Michopoulos, J.G.; Iliopoulos, A.P.; Singh Raman, R.K.; Phan, N.; Nguyen, T. Representing Crack Growth in Additively Manufactured TI-6AL-4V. Int. J. Fatigue 2018, 111, 610-622. [CrossRef]

14. Jones, R.; Raman, R.S.; Iliopoulos, A.P.; Michopoulos, J.G.; Phan, N.; Peng, D. Additively manufactured Ti-6Al-4V replacement parts for military aircraft. Int. J. Fatigue 2019, 124, 227-235. [CrossRef]

15. Iliopoulos, A.P.; Jones, R.; Michopoulos, J.G.; Phan, N.; Singh Raman, R.F.K. Crack growth in a range of additively manufactured aerospace structural materials, Special Issue, Civil and Military Airworthiness: Recent Developments and Challenges. Aerospace 2019, 5, 118. [CrossRef]

16. Kundu, S.; Jones, R.; Peng, D.; Matthews, N.; Alankar, A.; Singh Raman, R.K.; Huang, P. Review of Requirements for the Durability and Damage Tolerance Certification of Additively Manufactured Aircraft Structural Parts and AM Repairs. Materials 2020, 13, 1341. [CrossRef] [PubMed]

17. Jones, R.; Molaei, R.; Fatemi, A.; Peng, D.; Phan, N. A note on computing the growth of small cracks in AM Ti-6Al-4V. Procedia Struct. Integr. 2020, 111, 364-369. [CrossRef]

18. Sanaei, N.; Fatemi, A. Defect-based fatigue life prediction of L-PBF additive manufactured metals. Eng. Fract. Mech. 2021, 244. [CrossRef]

19. ASTM. Measurement of Fatigue Crack Growth Rates; ASTM: West Conshohocken, PA, USA, July 2016.

20. Sun, W.; Huang, W.; Zhang, W.; Qian, X. Effects of build direction on tensile and fatigue performance of selective laser melting Ti6Al4V titanium alloy. Int. J. Fatigue 2020, 130. [CrossRef]

21. Lincoln, J.; Melliere, R.A. Economic Life Determination for a Military Aircraft. AIAA J. Aircr. 1999, 36, 737-742. [CrossRef]

22. Niu, M.C.Y. Composite Airframe Structures: Practical Design Information and Data; Conmilit Press: Hong Kong, China, 1992.

23. Rouchon, J. Fatigue and Damage Tolerance Evaluation of Structures: The Composite Materials Response, National Aerospace Laboratory NLR, NLR-TP-2009-221, Rotterdam, The Netherlands. Available online: https:/ / reports.nlr.nl/handle/10921/224 (accessed on 2 February 2021).

24. Main, B.; Evans, R.; Walker, K.; Yu, X.; Molent, L. Lessons from a Fatigue Prediction Challenge for an Aircraft Wing Shear Tie Post. Int. J. Fatigue 2019, 123, 53-65. [CrossRef]

25. Jones, R.; Molent, L.; Barter, S. Calculating crack growth from small discontinuities in 7050-T7451 under combat aircraft spectra. Int. J. Fatigue 2013, 55, 178-182. [CrossRef]

26. Tan, J.L.; Chen, B.K. Prediction of fatigue life in aluminium alloy (AA7050-T7451) structures in the presence of multiple artificial short cracks. Theor. Appl. Fract. Mech. 2015, 78, 1-7. [CrossRef] 